Verfahren relative Abschätzung des Gehalts bei äusserst kleinen Eisenmengen; für genaue Bestimmungen ist es jedoch nicht verwendbar, da es, wie Damaskin zeigt, durchschnittlich um die Hälfte mehr Eisen ergibt, als die Titrirmethode. Ich verweise deshalb betreffs der näheren Ausführung, sowie betreffs sonstiger Einzelheiten auf das Original.

\title{
Ueber die Bestimmung der Homogentisinsäure und Gallussäure
} im Harn. ${ }^{1}$ ) Mit Rücksicht auf neuerliche Untersuchungen gibt E. B a u $\operatorname{mann}{ }^{2}$ ) folgende Vorschrift zur Bestimmung der Homogentisinsäure. $10 c c$ des Alkaptonharns werden in einem Kölbchen mit $10 c c$ Ammoniak von $3 \%$ versetzt. $\mathrm{Zu}$ dieser Mischung lässt man unverzüglich einige Cubikcentimeter $1 / 10$ Normal-Silberlösung fliessen, schüttelt einmal um und lässt 5 Minuten stehen. Alsdann werden der Mischung 5 Tropfen Chlorcalciumlösung (1:10) und 10 Tropfen Ammoniumcarbonat hinzugefügt. Nach dem Umschütteln wird filtrirt. Das bräunlich gefärbte aber immer ganz klare Filtrat wird mit Silbernitrat geprüft; tritt dabei sofort wieder eine starke Abscheidung von Silber ein, so wird bei dem zweiten Versuch gleich eine grössere (doppelte bis dreifache) Menge $1 / 10$ Normal-Silberlösung zu der Mischung von $10 \mathrm{cc}$ Harn und $10 \mathrm{cc}$ Ammoniak hinzugesetzt. Kennt man schon annähernd die zur Oxydation erforderliche Menge Silberlösung, so bedient man sich zur Erkennung der Endreaction nur der Prüfung mit Salzsäure. Die Endreaction ist erreicht, wenn das Filtrat vom Silberniederschlag beim Ansäuern mit verdünnter Salzsäure eine eben noch sichtbare Trübung von Chlorsilber liefert. Bei $4-6$ facher Wiederholung des Versuchs wird dieser Punkt scharf bestimmt. Sind mehr als $8 c c 1 /{ }_{10}$ NormalSilberlösung erforderlich gewesen, so muss bei Wiederholung des Versuches die auf $10 c c$ Harn zugefügte Ammoniakmenge auf $20 c c$ erhöht werden. $1 c c$ $1 / 10$ Normal-Silberlösung zeigt $0,004124 \mathrm{~g}$ Homogentisinsäure an,

Das Verfahren lässt sich nach C. Th. Mörner ${ }^{3}$ ) auch zur Bestimmung von Gallussäure im Harn benutzen. In Betreff der dabei einzuhaltenden Regeln verweise ich auf Mörner's Mittheilung.

Nachweis von Eiweiss, Albumosen und Peptonen. Der in Eiweisslösung durch Ferrocyankalium erzeugte Niederschlag gibt, wie

1) Vergl, diese Zeitschrift 30, 522.

2) Zeitschrift f. physiol. Chemie 16, 270.

3) Zeitschrift f, physiol. Chemie 16, 255. 